\title{
Is acquired pendular nystagmus always phase locked?
}

\author{
Jason J S Barton
}

\begin{abstract}
A patient with multiple sclerosis presented with oscillopsia due to an acquired pendular nystagmus that was dissociated in amplitude, being larger in the eye with a relative afferent pupil defect. Eye movement recordings showed an unusual dissociation in nystagmus frequency as well. Although the frequencies differed, the eyes remained phase locked as the right eye was oscillating exactly twice as fast as the left eye.
\end{abstract}

(F Neurol Neurosurg Psychiatry 1994;57:1263-1264)

Acquired pendular nystagmus can assume a wide variety of appearances. ${ }^{1}$ Its trajectory can be circular, oval, or linear along horizontal, vertical, or oblique axes. The nystagmus can also vary between the two eyes of the same patient. ${ }^{1-3}$ Monocular nystagmus has been reported, ${ }^{3-5}$ but more commonly the dissociation takes the form of asymmetries in the amplitude of oscillation or a difference in trajectory. ${ }^{3}$ An early finding by Aschoff et al, however, suggests that this independence of the two eyes is constrained by the fact that the nystagmus is phase locked even when dissociated. ${ }^{1}$ In other words, the frequency of these asymmetric oscillations is always the same in both eyes. I recently discovered a patient with dissociated pendular nystagmus whose ocular oscillations had different frequencies in the right and left eye.

\section{Case report}

A 35 year old woman presented with one year of oscillopsia, initially when viewing with the left eye only, and then with either or both eyes viewing. Snellen visual acuity was $20 / 40$ in the right eye and $20 / 200$ in the left eye. There was a $0.6 \mathrm{log}$ unit relative afferent pupil defect in the left eye and disc pallor bilaterally. She had a full range of ductions, but in all positions of gaze had a dissociated pendular nystagmus that was predominantly vertical in the left eye. The right eye had a small amplitude circular nystagmus that could only be appreciated on fundoscopy. The amplitude of pendular nystagmus decreased with convergence. Pursuit was impaired but saccades had good velocity and accuracy. Despite her lack of other symptoms her neurological examination showed a mild left sided pyramidal pattern of weakness with spasticity and hyper-reflexia, dysdiadocokinesia and intention tremor in the right limbs, and gait ataxia. Magnetic resonance imaging showed numerous periventricular lesions consistent with a diagnosis of multiple sclerosis. In particular there were plaques involving the right brainstem tegmentum and the left pontine tegmentum (fig 1).

Figure 1 Axial magnetic resonance images (TR 2400, TE 90). Note leftsided lesion in pontine tegmentum $(A)$ and rightsided lesion in midbrain tegmentum (B).
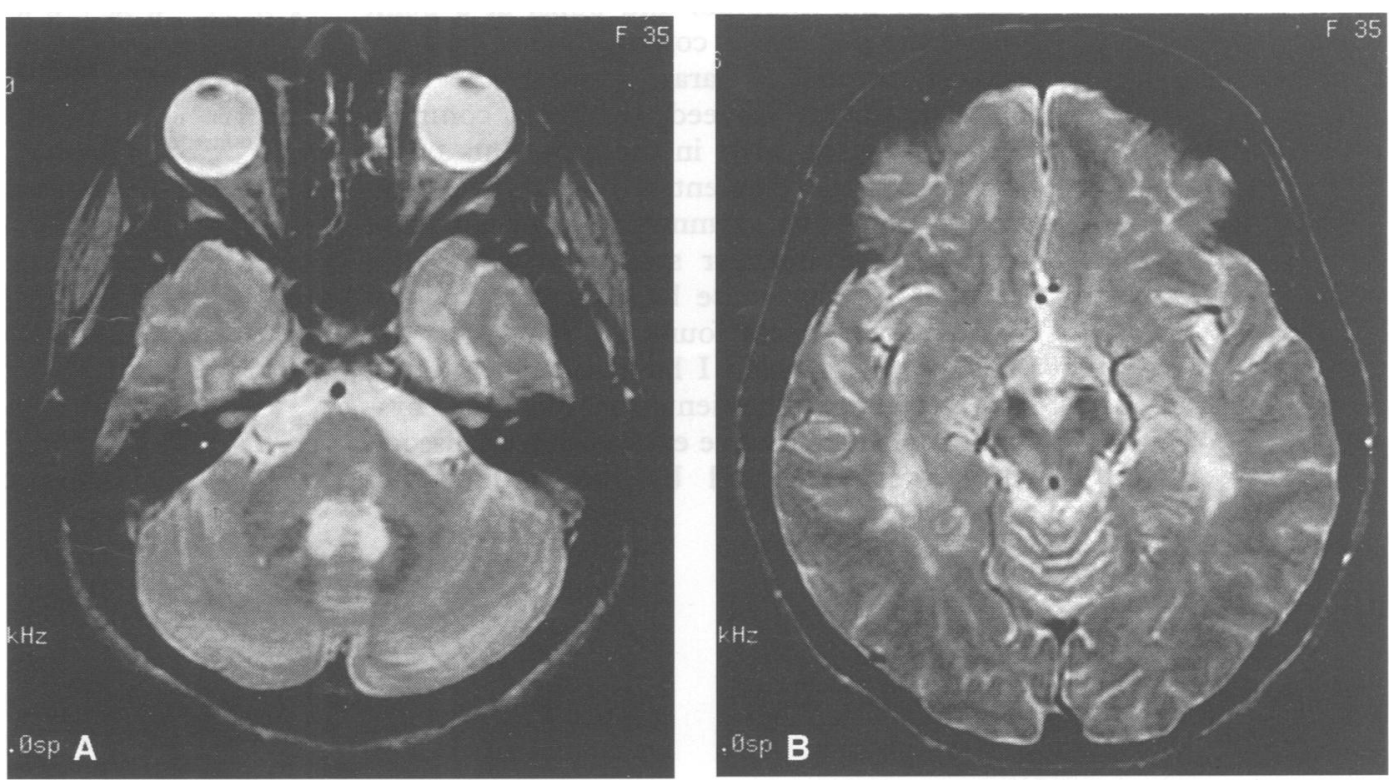
Figure 2 Magnetic search coil recording of nystagmus. Top two traces are right and left eye vertical position, bottom two traces are right and left eye vertical velocity. Pendular nystagmus is barely evident in the right eye position trace but is easily seen in the velocity trace. The right eye oscillates at twice the frequency of left eye oscillations. Note that the peak upward velocity in the left eye always coincides with a peak downward velocity in the right eye. Upbeat jerk nystagmus is indicated by the small arrow.
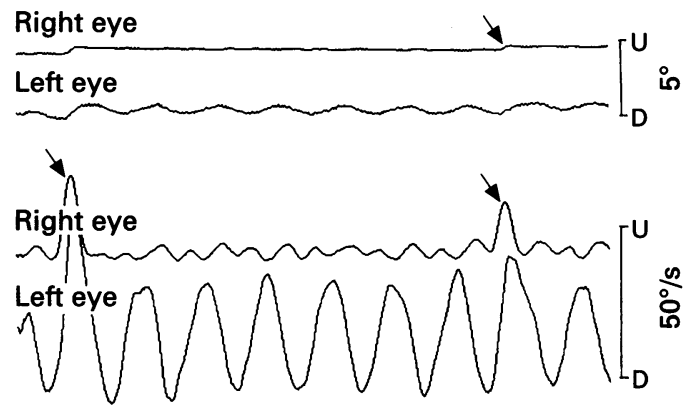

$500 \mathrm{~ms}$

\section{Eye movement recordings}

I recorded her horizontal and vertical eye movements on two occasions with two dimensional magnetic-search-coil oculography (fig 2). Recordings were made on a rectilinear inkjet polygraph, stored on magnetic tape, and digitised on line at $500 \mathrm{~Hz}$ on a PDP 11/73 computer. There was a pendular nystagmus in the position tracing of the left eye, with horizontal and vertical components. In the position tracings of the right eye there was a small amplitude upbeat jerk nystagmus in primary position and upgaze, but pendular nystagmus was difficult to see. The velocity tracings showed pendular oscillations in both eyes, with higher velocities in the left eye. Not only was the amplitude of nystagmus dissociated in the two eyes, however, but the frequency of oscillation was also different. A closer inspection of the magnified digitised tracing showed that the right eye was oscillating at exactly twice the frequency of the left. Every second peak of downward right eye velocity coincided with the peak upward velocity of the left eye (fig 2 , velocity traces).

\section{Discussion}

Most forms of nystagmus are symmetrically expressed in the two eyes. The finding of dissociations in acquired pendular nystagmus led Gresty et al to propose that the site of pathology must be close to the ocular motor nuclei in the midbrain and pons, at a point where the prenuclear commands for each eye diverge on their separate ways to the right and left nuclei. ${ }^{2}$ Indeed, the most common lesions seen on MRI in these patients occur in the pontine tegmentum, ${ }^{3}$ as was seen in this patient. The asymmetric involvement of immediate prenuclear structures would not account for the phase locking of nystagmus frequency that was found by Aschoff et al, ${ }^{1}$ however, and which I have seen in most of my recordings of patients with pendular nystagmus. An alternative explanation of dissociation was suggested by the finding that asymmetries in nystagmus correlate with asymmetries in optic neuropathy in multiple sclerosis, ${ }^{3}$ implying a role for impaired visual feedback in the genesis of pendular nystagmus. This is analagous to the development of monocular pendular nystagmus after unilateral visual loss. ${ }^{6-9}$

This report expands the range of dissociation possible in acquired pendular nystagmus. Not only can trajectory and amplitude differ between the two eyes, but frequency can also vary. I am not aware of any report of a similar dissociation in the frequency of acquired pendular nystagmus. Perhaps more importantly, there was still a constant phase relation between the two eyes in this patient, in that the frequency of right eye oscillations was precisely twice that of the left. This contrasts with the findings in spasmus nutans, where it is reported that the phase relation can vary within the same recording session. ${ }^{10}$ Therefore, for acquired pendular nystagmus the implication of the original observation of Aschoff et al on phase locking remainsnamely, that some conjugate control is present in the expression of this abnormal eye movement. ${ }^{1}$ Given the high frequency of cerebellar signs occurring in patients with acquired pendular nystagmus, this abnormality likely involves an impairment of cerebellar ocular motor structures or their connections in the brain stem. ${ }^{13}$ How such an impairment led to the unusual phase locked dissociation of nystagmus frequency in this patient remains unclear.

$P$ Nguyen and Dr AG Huaman assisted with the ocular P Nuyen and Dr AG Huaman assisted with the ocular recordings. This work was supported by Medical
Council of Canada grant $9004 \mathrm{FEN}-1222-21813$.

1 Aschoff JC, Conrad B, Kornhuber HH. Acquired pendular nystagmus with oscillopsia in multiple sclerosis: a sign of cerebellar nuclei disease. $\mathcal{F}$ Neurol Neurosurg Psychiatry 1974;37:570-7.

2 Gresty MA, Ell JJ, Findley LJ. Acquired pendular nystagmus: its characteristics, localizing value and pathophysimus: its characteristics, localizing value and pathophys

3 Barton JJS, Cox TA. Acquired pendular nystagmus in multiple sclerosis: clinical observations and the role of optic neuropathy. I Neurol Neurosurg Psychiatry 1993; 56:262-7.

4 Koerner F. Acquired and congenital monocular pendular nystagmus. A comparative electronystagmographic study of two cases. Albrecht v Graefes Arch Klin Exp Ophthalmol 1975;197:165-75.

5 Castaigne P, Chain F, Pierrot-Deseilligny C, Larmande P. Le nystagmus de circumduction monoculaire. Rev Neurol (Paris) 1979;135:51-7.

6 Smith JL, Flynn JT, Spiro HJ. Monocular vertical oscillations of amblyopia: the Heimann-Bielschowsky phenomenon. $¥$ Clin Neuroophthalmol 1982;2:85-91

7 Yee RD, Jelks GW, Baloh RW, Honrubia V. Uniocular nystagmus in monocular visual loss. Ophthalmol 1979; 86:511-8.

8 Stangler-Zuschrott E. Störungen der Okulomotorik während Punktfixation des führenden Auges bei einseit-
iger Deprivationsamblyopie, Schielamblyopie und einiger Deprivationsamblyopie, Schielamblyopie und einseitigem Organschaden. Klinische Monatsblaffer fur Augenheilkunde 1987;191:403-8.

9 Leigh RJ, Thurston SE, Tomsak RL, Grossman GE, Lanska DL. Effect of monocular visual loss upon stabity of gaze. Invest Ophthalmol Vis Sci 1989;30:288-92.

10 Weissman BM, Dell'Osso LF, Abel LA, Leigh RJ. Spasmus nutans. A quantitative prospective study. Arch Ophthalmol 1987;105:525-8. 